Coelho, P. \& Abreu, N. (2017). Inclusão da criança com deficiência visual em serviços de ensino sob a perspectiva da pesquisa transformativa do consumidor. Consumer Behavior Review, 1(Special Edition) 49-61.

ISSN: 2526-7884

Editor: Prof. Dr. Marconi Freitas da Costa Email da revista: cbr@ufpe.br
Avaliação: Double blind review

Recebido: 10 de julho de 2017

Aceito: 26 de setembro de 2017

\title{
INCLUSÃO DA CRIANÇA COM DEFICIÊNCIA VISUAL EM SERVIÇOS DE ENSINO SOB A PERSPECTIVA DA PESQUISA TRANSFORMATIVA DO CONSUMIDOR
}

Pedro Coelho

Nelsio Abreu

\section{Pedro Coelho é Doutorando em}

Administração e Controladoria pela

Universidade Federal do Ceará - UFC. E-mail: pedrofelipecc@gmail.com.

Nelsio Abreu é Professor Associado da

Universidade Federal da Paraíba - UFPB. Email: nelsio@gmail.com.

Os autores agracedecem aos avaliadores pelos comentários para melhoria do artigo.

\begin{abstract}
Resumo
Esta pesquisa teve por objetivo analisar o papel de docentes no processo inclusivo de alunos deficientes visuais do ensino fundamental. Para tanto, procedeu-se um estudo qualitativo, onde os dados foram coletados por meio de entrevistas narrativas com 16 alunos deficientes visuais do ensino fundamental e de entrevistas em profundidade com cinco responsáveis desses alunos e seis gestores e professores de uma ONG que lida com deficientes visuais.Os resultados apontam que os professoressão atores que podem promover a inclusão dos alunos, através do estímulo à integração dos alunos com os demais colegas e da adaptação das ferramentas de ensino. Contudo, os docentes podem estimular a adoção práticas exclusivas, ignorando a presença de tais alunos em sala de aula ou manifestando a sua descrença no potencial de aprendizado das crianças.

Palavras-chave: Pesquisa Transformativa do Consumidor, Inclusão escolar, Deficiência visual.
\end{abstract}

Esta obra está licenciada com uma Licença Creative Commons Atribuição 4.0 Internacional.

\section{INTRODUÇÃO}

A Pesquisa Transformativa do Consumidor tradução literal de Transformative Consumer Research (TCR) - é um movimento internacional que tem o objetivo de compreender os efeitos do consumo na melhoria do bem-estar do consumidor, por meio do estudo de situações práticas de consumo (Micket al., 2012). Pesquisas desenvolvidas à luz da abordagem 
consideram problemas sociais que eram pouco atentados por pesquisadores de marketing, além de incorporar nas investigações públicosalvo que comumente são ignorados por tais acadêmicos, como pessoas com deficiência.

A despeito do recente interesse de pesquisadores brasileiros em estudar práticas de consumo com vistas para o bem-estar individual e coletivo das pessoas (Barbosa, 2014; Faria, 2015; Coelho, 2015; Pinto et al., 2016), ainda é incipiente a produção científica em marketing direcionada ao comportamento de consumo de pessoas com deficiência, especialmente no que se refere ao consumo de serviços de educação.

Deficiente ou não, qualquer aluno, em algum momento de sua vida acadêmica, está sujeito a apresentar dificuldades, que podem ser traduzidas por necessidades educacionais. Caso isso aconteça, espera-se que os professores conheçam estratégias para contornar a situação, ajudando-o a superá-las (Lippeet al., 2012). Contudo, as falhas cometidas por tais atores são recorrentes e se manifestam de diferentes maneiras quando as instituições de ensino se deparam com alunos deficientes visuais, devido ao despreparo e ao preconceito perante estes alunos (Razuck \& Guimarães, 2014). Em função disso, discussões relativas à inclusão educacional vêm sendo desenvolvidas.

A inclusão no ambiente escolaralmeja a garantia de que todos os alunos, independente de suas capacidades, alcancem todo seu potencial em local escolar apropriado (Alves \& Duarte, 2014). Embora se saiba que a inclusão educacional é um direito garantido pela legislação educacional vigente (BRASIL, 1996; 1998; 2001; 2008; 2015b), estudos recentes evidenciam que as intervenções educativas para os deficientes visuais no Brasil encontram-se comprometidas em função da falta de recursos didáticos adequados, da exclusão tecnológica, da didática baseada exclusivamente no visual e, principalmente, do despreparo docente para o ensino dos deficientes visuais (Costa, Neves, \& Barone, 2007; Fernandes, 2011; Zucherato \& Freitas, 2011; Razuck \& Guimarães, 2014; Figueiredo \& Kato, 2015).

Dados do mais recente censo escolar indicam que houve um crescimento do número de matrículas de alunos com deficiência na educação básica regular. Em 1998, cerca de 200 mil alunos que possuíam algum tipo de deficiência estavam matriculados na educação básica, sendo apenas 13\% em classes comuns. Em 2014, eram quase 900 mil matrículas e 79\% deles em turmas comuns (Brasil, 2015a). Apesar disso, os dados não retratam que os alunos têm tido acesso ao conhecimento e ao aprendizado dos conteúdos escolares, pois o sucesso da implementação de políticas públicas não se representa somente por números (Laplane \& Caiado, 2012).

Tanto nas universidades (Regiani \& Mol, 2013; Coelho, Orsini, \& Abreu, 2016) quanto nas escolas (Vilaronga \& Caiado, 2013) práticas exclusivas são manifestadas, sendo responsáveis, inclusive, pelo abandono dos alunos das instituições de ensino. Quando tais práticas ocorrem no ensino fundamental, os alunos cegos ou com baixa visão perdem a oportunidade de se alfabetizarem, além de serem estimulados ao isolamento da sociedade (Fiorini, Deliberato, \& Manzini, 2013).

Diante dessa carência de publicações sobre a temática; do elevado percentual de alunos com deficiência matriculados; e da diversidade de equívocos cometidos por professores do ensino fundamental, esta pesquisa teve por objetivo analisar o papel docente no processo inclusivo de alunos deficientes visuais do ensino fundamental.

Estudos voltados para a inclusão de deficientes visuais no ensino fundamental, em sua maioria, são oriundos da Educação e enfocam na sala de aula, retratando as dificuldades dos alunos nas aulas de matemática (Rosa \& Baraldi, 2015), física (Barbosa-Lima \& Gonçalves, 2014) e química (Regiani \& Mol, 2013). Porém, consideramos que as falhas cometidas pelas escolas (prestadoras de serviços) também podem ser investigadas sobre o olhar de Marketing, uma vez que os alunos com deficiência visual são consumidores com necessidades e desejos de consumo. Dessa forma, pretende-se analisar o papel docente no processo inclusivo a partir do olhar do consumidor (aluno) e de prestadores de serviços (docentes e gestores escolares).

\section{A TCR E O CONSUMIDOR DEFICIENTE VISUAL}

A TCR é um movimento que visa incentivar, apoiar e divulgar pesquisas que primam pelos benefícios, bem-estar e qualidade de vida dos 
seres humanos afetados pelo consumo no mundo (ACR, 2017), através do estudo de problemas significativos para os consumidores e que possam gerar resultados para o seu benefício (Petkus, 2010).

A Pesquisa Transformativa do Consumidor, contudo, não deve ser vista um movimento que desconsidera e critica a realização de estudos inseridos no mainstream das pesquisas em comportamento do consumidor, nem umaabordagem que objetiva substituir o foco gerencial nas pesquisas sobre o consumo. Apesquisa transformativa do consumidor lança um novo olhar sobre o consumo, umaperspectiva distinta da convencional, e não antagônica (Coelho, 2015).

Embora seja um movimento recente, pesquisadores de países distintos estão difundindo os achados dos seus estudos em journals consagrados, como o Journal of Research for Consumers, o Journal of Public Policy \& Marketing e o Journal of Business Research (Davis \& Pechmann, 2011). Dentre os grupos de consumidores considerados nos estudos transformativos, destacam-se os deficientes visuais, objetos desta pesquisa.

Os consumidores com deficiência visual enfrentam barreiras físicas - dificuldades de locomoção em calçadas, transportes públicos e escadas (Faria \& Motta, 2012) e, principalmente, barreiras atitudinais, que resultam do despreparo e prestadores de serviço público e privado para atender esse grupo de consumidores (Farias, Silva, \& Ferreira, 2012). A falta de adaptações no layout e checkoutdas lojas e a estigmatização nos ambientes de consumo (Bakeret al., 2001) dificultam o desfrute de experiências de consumo positivas.

0 último aspecto foi evidenciado em Faria, Silva e Ferreira (2012), que retrataram essa realidade ao denunciarem que alguns deficientes visuais deixam de frequentar restaurantes devido ao preconceito dos atendentes e dos próprios consumidores, que comentam sobre o modo como eles fazem suas refeições. Outros estudos também analisaram a prestação de serviço ao deficiente visual. Baker et al. (2007) estudaram as experiências de acessibilidade dos consumidores deficientes visuais em bancos, restaurantes, hospitais e padarias, enquanto Childers e KaufmanScarborough (2009) e Kaufman-Scarborough e
Childers (2009) analisaram as experiências de consumo em compras online. Nos três estudos foi concluído que a acessibilidade também está vinculada às atitudes dos prestadores de serviços durante o atendimento à pessoa com deficiência.

Ademais, é importante destacar que os próprios consumidores deficientes visuais são resilientes e encontram alternativas para adaptarem-se a essas práticas do mercado, através da utilização de fontes alternativas de informação (buscando na memória, escutando comerciais, amigos e familiares) para ajudá-los no processo de decisão (Amaroet al., 2008; Coelho, Orsini, \& Abreu, 2016), bem como os demais elementos sensoriais são desenvolvidos para compensar a limitação visual (Pinto \& Freitas, 2013).

Especificamente sobre o consumo de serviços educacionais, as primeiras medidas adotadas relacionadas ao ensino para a deficientes visuais no Brasil tiveram um caráter de exclusão e ocorreram por meio da criação de escolas especiais que se destinavam unicamente à educação de pessoas com deficiência (Santos \& Vieira, 2006; Gorni, 2007).

Com a evolução das pesquisas sobre saúde e educação, verificou-se que, dependendo das perspectivas de habilitação e reabilitação, esses alunos poderiam estudar em escolas regulares, desde que fossem oferecidos a elas instrumentos e equipamentos adequados de apoio (Fernandes, 2006; Leite, 2013). Outros aspectos relativos ao consumo em serviços educacionais, com ênfase para a inclusão escolar e o papel docente, serão tratados a seguir.

\section{INCLUSÃO ESCOLAR E O PAPEL DOCENTE}

A inclusão se relaciona à igualdade de oportunidades para todas as pessoas da sociedade. Tais práticas são fomentadas, geralmente, por políticas públicas nas diversas áreas de atuação do Estado - como a saúde e educação - e direcionadas para grupos de cidadãos diversos (Viralonga \& Caiado, 2013).

Especificamente sobre a inclusão de pessoas com deficiência, Franco (2007) afirma que o deficiente precisa lidar com o excesso de piedade de uma sociedade que ainda se encontra despreparada para atendê-los. Esse 
despreparo também é manifestado na educação, espaço onde os alunos deveriam ser estimulados ao diálogo com as pessoas videntes, mas que, em muitos casos, depara-se com o oposto (Sigolo, 2008).

Oliveira (2006) destaca que a inclusão nas escolas exige uma reflexão crítica da comunidade escolar e o repensar em oportunidades educacionais que propiciem a aprendizagem dos componentes curriculares por todos os alunos. O contexto escolar deve propiciar a inserção de todos os alunos, seja em ambiente público, seja privado, de modo acolhedor, com respeito, além de ofertar qualidade de ensino, independente da necessidade educacional especial que apresentem (Castaman, 2006).

De fato, as próprias diretrizes da educação básica do Brasil destacam isso, salientando que a inclusão educacional se assenta em uma proposta que reúne importantes valores simbólicos, compatíveis com a igualdade de oportunidades e direitos, oferecidos para todos os alunos, em um ambiente educacional adequado (BRASIL, 1996). Porém, mesmo com as mudanças políticas e com os novos e muitos documentos produzidos na área, a crença na incapacidade e na falta de potencial das pessoas com deficiência, impede mudanças nos processos de escolarização na direção do direito pleno à escolarização (Ferreira, 2006).

Especificamente sobre os deficientes visuais, as instituições de educação cada vez mais recebem alunos com essa condição, sendo responsáveis por incluí-los neste novo espaço social e adaptando-os ao convívio dos ditos normais e vice-versa. Este convívio irá proporcionar, por meio da interação deficiente visual/dito normal, a formação de um autoconceito positivo ou negativo de si (Mantoan, 2002).

0 autoconceito positivo está inteiramente relacionado à realização contínua de um trabalho de sensibilização da comunidade escolar, assim como a realização de cursos de atualização para profissionais de ensino, adaptações nas estruturas físicas e curriculares das escolas, de maneira a quebrar barreiras arquitetônicas, pedagógicas e atitudinais, além de impulsionar o aperfeiçoamento das práticas pedagógicas empreendidas (Viralonga \& Caiado, 2013).
A inclusão de um aluno cego ou com baixa visão nas escolas e demais instituições de ensino também está diretamente relacionada com as atividades desenvolvidas em sala de aula(Dall'acqua, 2002). Contudo, grande parte das escolas não se encontra preparada para receber alunos com deficiência visual pelo simples fato de não estarem dando conta de alcançar seus objetivos educacionais nem mesmo junto aos alunos considerados "normais". Além disso, o desconhecimento por parte dos sujeitos que compõem a escola explica a sensação de desconforto e reforça a resistência à inclusão escolar (BRASIL, 2008).

A postura do professor na sala de aula, segundo Vygotsky (1997), determina ou não a aprendizagem dos alunos, por meio de mediações e trocas simbólicas, favorecendo o seu desenvolvimento. 0 professor poderá adaptar as atividades para os alunos com cegueira, utilizando sementes de diversas texturas para que o aluno possa identificar cada elemento da atividade. No caso dos alunos com baixa visão, o material deverá ter cores fortes ou contraste para que melhor se adapte à limitação de cada aluno, ou que as fontes sejam ampliadas, podendo estas ser alternativas essenciais no seu processo de aprendizagem (Oliveira, 2007). Diante disso, faz-se necessário que as escolas e principalmente os professores da sala regular se preparem para o atendimento aos alunos que possuem deficiência.Porém, diversas dificuldades são enfrentadas por esse grupo de alunos. 0 acesso ao livro, que é relativamente fácil para as pessoas videntes, torna-se difícil para os deficientes visuais, que ficam dependentes de instituições que disponibilizam livros em braile para leitura ou da boa vontade de pessoas que leiam para eles (Pinheiro et al., 2008).

\section{PROCEDIMENTOS METODOLÓGICOS}

Para alcançar o objetivo do estudo, realizouse uma pesquisa exploratória de caráter qualitativa. Também é possível classificar o estudo como um pesquisa transformativa em parceria (Mick et al., 2012), uma vez que buscou-se a produção de conhecimento científico voltado para o bem-estar dos consumidores em parceria com organizações sociais.Os dados foram coletados em uma ONG (aqui denominada de ONG Vida) que atua na 
educação de crianças com deficiência visual. 0 acesso aos sujeitos de pesquisa foi facilitado pela atuação do primeiro autor como professor voluntário na instituição durante o período da coleta de dados.

Duas técnicas de coleta de dados foram adotadas: entrevista narrativa e entrevista em profundida. A primeira foi realizadacom 16 alunos do ensino fundamental, por ser uma técnica capaz de evidenciar aspectos nebulosos da realidade de um grupo de pessoas a partir de discursos individuais coletados em uma situação rotineira do entrevistado (Jovchelovich \& Bauer, 2002). Já as entrevistas em profundidade foram conduzidas com seis gestores e professores da ONG Vida e cinco responsáveis desses alunos,em função de sua aplicabilidade quando o objetivo da investigação exige que se compreenda com profundidade o mundo no qual vivem os sujeitos, particularmente quando eles são difíceis de ser recrutados (Gaskell, 2002).

A coleta de dados foi iniciada com a realização das entrevistas narrativas. Os diálogos ocorreram em diferentes momentos com os mesmos sujeitos de pesquisa, devido à dificuldade de ter a atenção das crianças por muitos minutos - até mesmo em conversas informais. Foram feitas 93 entrevistas narrativas que tiveram 14 minutos de duração em média. 0 diálogo de menor duração durou 6 minutos e o mais longo, 31. Todas as entrevistas ocorreram dentro da instituição e foram realizadas antes, durante, no intervalo ou depois das aulas de crianças que frequentavam, no mínimo, semanalmente a ONG (Tabela 1).

Tabela 1

Perfil dos alunos entrevistados

\begin{tabular}{|c|c|c|c|c|c|}
\hline Pseudônimo & Idade & Série & Tipo de deficiência visual & $\begin{array}{l}\text { Cidade onde } \\
\text { reside }\end{array}$ & $\begin{array}{l}\text { Tipo de } \\
\text { escola }\end{array}$ \\
\hline Ana & 8 & $2^{\circ}$ & Totalmente Cega & João Pessoa & Pública \\
\hline Bruna & 10 & 40 & Cega de um olho & Guarabira & Pública \\
\hline Cláudia & 12 & 7 o & Totalmente Cega & João Pessoa & Particular \\
\hline Denise & 11 & $5^{\circ}$ & Pequena percepção luminosa & João Pessoa & Particular \\
\hline Elena & 15 & $8^{0}$ & Totalmente Cega & Sapé & Pública \\
\hline Fernanda & 9 & 40 & Baixa visão & João Pessoa & Pública \\
\hline Geórgia & 7 & $1^{\mathrm{o}}$ & Baixa visão & Santa Rita & Pública \\
\hline Hortência & 16 & 9o & Totalmente Cega & João Pessoa & Pública \\
\hline Iara & 14 & $9 \underline{0}$ & Totalmente Cega & João Pessoa & Particular \\
\hline Joana & 9 & $4 \underline{0}$ & Baixa amplitude visual & João Pessoa & Particular \\
\hline Lauro & 10 & 30 & Totalmente Cego & Santa Rita & Pública \\
\hline Mauro & 10 & $4^{\mathrm{o}}$ & Pequena percepção luminosa & João Pessoa & Particular \\
\hline Nando & 9 & $4^{\circ}$ & Totalmente Cego & João Pessoa & Particular \\
\hline Otávio & 12 & $7 \underline{0}$ & Totalmente Cego & Sapé & Pública \\
\hline Paulo & 12 & $6^{0}$ & Pequena percepção luminosa & João Pessoa & Púbica \\
\hline Queiroz & 13 & $8^{\circ}$ & Pequena percepção luminosa & Bayeux & Pública \\
\hline
\end{tabular}

Fonte: Elaborado pelos autores (2017).

Como se observa na Tabela 1, os sujeitos de pesquisa investigados residem na região metropolitana de João Pessoa, possuem entre 7 e 16 anos e, em sua maioria, não iniciaram os estudos na idade ideal ou repetiram alguma série, o que justifica a disparidade entre as idades dos alunos e suas séries. Elena, por exemplo, é uma aluna com 15 anos e, portanto, já deveria estar cursando o ensino médio, mas ainda se encontra no fundamental. 
Para as entrevistas em profundidade, foram selecionados seis profissionais com experiência mínima de 5 anos no atendimento ao deficiente visual, que possuem formações distintas e diferentes lentes sobre a inclusão escolar. Já os responsáveis pelos alunos são pessoas que frequentemente levam as crianças para a ONG Vida e ficam nas dependências da instituição até que as atividades sejam encerradas. As entrevistas com os profissionais da ONG e com os responsáveis duraram em média uma hora.

Os dados foram analisados segundo a "Espiral de análise de dados" desenvolvida por Creswell (2007). Depois da organização das informações em pastas, foi feita a leitura das transcrições das entrevistas narrativas e em profundidade, sendo possível obter uma noção geral dos dados antes que eles fossem "reduzidos" a códigos.Após a leitura, foram criados códigos que permitiram a identificação de temas em comum nos materiais coletados. Depois de comparados, os principais temas foram identificados e o material foi lido novamente com o objetivo de fazer interpretações à luz do referencial teórico e agrupá-los em tópicos. 0 processo de análise dos dados foi encerrado com a validação dos resultados pelos gestores e professores da ONG entrevistados - memberchecks.

Ressalta-se que as crianças que participaram do estudo foram autorizadas por seus pais, que deram permissão para a gravação dos diálogos com seus filhos. Alguns pediram para ler o roteiro de entrevista e outros perguntaram se as identidades das crianças seriam preservadas. Os demais respondentes - responsáveis dos alunos e colaboradores da ONG - também foram informados que suas identidades seriam preservadas, bem como o nome da própria ONG. Não houve recompensa financeira para a participação da pesquisa, que possui os seus resultados descritos em seguida.

\section{ANÁLISE DOS RESULTADOS}

Este tópico apresenta a análise dos principais resultados deste estudo. A partir da espiral de análise de dados descrita anteriormente, os sub-tópicos abaixo foram selecionados. Os sub-tópicos, portanto, derivaram do processo de codificação, classificação, agrupamento e análise do material coletado, e não foram previamente estabelecidos. Inicialmente, a atuação docente na integração inicial dos alunos será discutida, com ênfase para o papel dos professores na integração dos alunos deficientes visuais nos primeiros dias de aula. Em seguida, iniciativas voltadas para a adaptação das ferramentas de ensino serão discutidas. Por fim, as principais falhas e acertos na prestação de serviço do professor serão tratados.

\section{Atuação docente na integração inicial dos alunos}

A integração inicial do aluno deficiente visual na sala de aula com os demais colegasé um momento marcado pela influência do professor. Certamente, promover a interação dos alunos, incentivar a realização de atividades instigantes à criança cega ou com baixa visão, prestar esclarecimentos sobre o que é deficiência para alunos videntes e seus pais não são as únicas atribuições de um professor disposto a promover a inclusão de seus alunos. Contudo, esta etapa do processo de inclusão é crucial para os alunos e, na perspectiva dos seus responsáveis, é um momento marcado pela angústia.

Trata-se de uma das primeiras situações em que as crianças são colocadas em um ambiente sem a presença de um familiar. 0 medo da reação dos demais alunos e a desconfiança da capacidade da escola de promover a inclusão educacional justificam o sentimento de angústia da família. Alguns familiares, inclusive, não foram capazes de deixar seus filhos na escola e permaneceram nas instituições até o fim das aulas. 0 depoimento de uma responsável ilustra os sentimentos envolvidos neste momento para a família:

\footnotetext{
Eu não conseguia ir pra casa, ficava olhando como ela se comportava, se tava brincando com os coleguinhas. Ela se comportava muito bem, não dava trabalho em nada... Era mais quieta que os outros... Muito mais. O problema era comigo mesmo. Ficava achando que alguma coisa ruim ia acontecer com ela, alguém ia maltratar ela (RESPONSÁVEL 2).
}

A transcrição acima está alinhada às conclusões de Oliveira (2007), que encontrou resultados similares aos deste estudo. Para as crianças entrevistadas, o primeiro contato com 
os seus colegas de classe foi um momento que ocorreu, geralmente, com o incentivo dos professores. Algumas dinâmicas de socialização - como as atividades de desenho em dupla, pinturas coletivas e as brincadeiras coletivas com massinha - contribuíram para a aproximação dos alunos. Em outros casos, prevaleceu a falta de sensibilidade dos educadores diante da deficiência. Foi pedido para que as crianças descrevessem objetos, falassem de si, caminhassem fora da sala de aula para conhecer as dependências da escola ou desenvolvessem outras atividades que inibiram a participação dos alunos entrevistados.

Alguns eventos foram relatados pelos alunos, que exprimiram insegurança e vergonha para descrever os momentos negativos, além de medo da represália dos professores. Portanto, tais relatos só foram obtidos no final da coleta de dados deste estudo, quando já havia uma maior aproximação entre entrevistador e entrevistado.

(...) não fiquei triste na hora, só depois. Conversei com "mainha" e ela me acalmou mais... Então eu voltei [para escola] no outro dia. Mas fiquei triste, porque a professora disse na sala que era pra todo mundo ter cuidado comigo, cuidado pra não esbarrar em mim. Disse que todo dia alguém ia anotar as tarefas na minha agenda. E não falava comigo, falava com os outros. Como se eu não tivesse na sala (JOANA).

Na primeira semana a professora disse que a turma ia receber uma aluna "ceguinha". Eu tenho nome e não gosto quando me chamam disso (FERNANDA).

0 primeiro relato ilustra uma prática nociva do mercado já abordada por Damascena e Farias (2013) e Coelho, Orsinie Abreu (2015): a crença de que a PcD é invisível nos ambientes de serviço. Assim como os varejistas de supermercados e de shopping centers, alguns docentes também ignoraram a presença dos alunos com deficiência visual e direcionaram o discurso para as demais pessoas videntes que estavam no mesmo ambiente.

Além das falhas cometidas pelos educadores, como relatado por Joana e Fernanda, a criança deficiente visual é desafiada desde o primeiro de aula a frequentar novos espaços físicos despreparados para PcD. Em função dos problemas na estrutura física das escolas, a construção de laços de amizade com professores e alunos - como relatado por Lippe, Alves e Camargo (2012) - também contribui para a locomoção dos alunos na escola durante os primeiros meses de aula.

Complicado mesmo foi no começo, que eu não conhecia ninguém. Tive que mudar de escola, porque "mainha" mudou de emprego e não podia mais me levar de tarde. Então, quando cheguei lá [na nova escola], foi ruim, porque demorei pra me adaptar. A escola é meio isolada e eu demorei pra me localizar lá dentro, tinha muita gente, muito barulho... Quem me ajudou foi Rosana, minha amiga. Desde o começo, foi ela quem fez tudo por mim, me ajudava nas tarefas, ia comigo no banheiro (HORTÊNCIA).

Foi ruim, professor... Muito ruim. A professora até que tentava me ajudar, mas não tinha como me levar pros cantos [da escola]. A sorte foi que ela sempre colocava alguém [da turma] pra cuidar de mim, e nessa história eu conheci meus amigos. Agora a gente faz tudo junto, até jogar bola. E quando eles não podem, a "tia" me ajuda (QUEIROZ).

A integração entre os alunos bem conduzida pelos professores no início do período letivo é capaz de quebrar barreiras. Diversos esclarecimentos devem ser oferecidos aos alunos videntes e aos seus pais sobre a deficiência e suas características. A concepção deturpada sobre a PcD, certamente, também é fruto da falta de informaçãoe do estereótipo negativo reforçado pelos meios de comunicação, o que reforça a responsabilidade do professor diante quebra de preconceitos, como o relato abaixo demonstra.

Lá na minha escola tem, eu vivo lá. Quando acabam as aulas, eu venho pra cá ou continuo por lá. Faço minhas tarefas, leio meus livros... É ótimo (JOANA).

Eu vivo lá na sala... Na SAAI [Sala de Atendimento e Apoio à Inclusão]. Deixo meus livros por lá mesmo, o senhor sabe como são pesados. Ai vou pra lá todo dia, às vezes passo o dia por lá mesmo. Aprendi o Braille na ONG Lar e na SAAI, tinha (PAULO).

A partir dos relatos, percebe-se que o professor é um ator capaz de iniciar o debate de práticas inclusivas em sala de aula, promover a interação entre os alunos videntes e com deficiência, realizar adaptações na estrutura física das salas e nos materiais didáticos da 
escola, dentre outras funções. A despeito dessa gama de práticas inclusivas que podem ser desenvolvidas pelos educadores, o professor também pode ser o precursor de uma série de atos exclusivos nos primeiros dias de aula, caso possua uma visão deturpada sobre o aluno deficiente ou não seja capaz de adaptar suas ferramentas de ensino. 0 último aspecto será discutido a seguir.

\section{Adaptações das ferramentas de ensino}

Os resultados da pesquisa indicam que a adaptação das ferramentas de ensino é uma tarefa árdua para os docentes, principalmente àqueles sem experiência em ensinar PcD. Apesar de alguns professores possuírem interesse em ajudar o aluno cego a aprender, em muitos casos ele não sabe como. De fato, o aluno com deficiência visual precisa, necessariamente, de materiais especiais que permitam o seu aprendizado, como livros e exercícios em Braille, máquina de escrita em Braille (ou textos em fonte Arial 24 e cadernos com pautas largas, caso a criança apresente baixa visão). Nesse sentido, os professores adotaram estratégias alternativas para suprir a necessidade dessas ferramentas:

Dou aula em Mangabeira, na escola que eu ensino não tinha DOSVOX [sistema operacional que permite a utilização de computadores para pessoas cegas desempenharem tarefas diversas]. Era difícil explicar pra um aluno cego o que é um computador e pra quê ele serve, se ele não podia utilizá-lo. Então, pesquisei algumas na Internet algumas ferramentas de ensino que me ajudaram. Meus alunos utilizavam o computador convencional e eu pedia para um aluno vidente dizer o que tinha na tela. Ou então, na maioria das vezes, eu levava meu notebook para a sala e dava a aula pra eles (...). Mas tinham coisas que realmente não davam, sem utilizar os outros sentidos o processo de aprendizagem fica bem difícil (PROFESSOR 1).

Sim, é comum não ter livros em Braille nas escolas. A gente faz o que pode, traz eles pra cá, arranja livro emprestado. Mas, no meu caso, é pior, porque livro de inglês é difícil de achar. Acho que tem pouca demanda (...). Eu dava aula com o livro normal e utilizava outra metodologia de ensino. É até engraçado, porque depois descobri que tão utilizando a mesma metodologia pros alunos videntes (...). É baseada na conversação, o aluno precisa escrever pouco e conversar mais. Ele é forçado a interagir verbalmente o tempo todo, expandindo o vocabulário e formulando frases. Dificulta bastante na escrita, essa é a hora que o livro faz falta. Mas a compreensão deles é muito boa, os sentidos aguçados... Tenho alunos melhores que os videntes. Não são poucos (PROFESSOR 2).

A lentidão da impressão dos textos adaptados foi outra falha mencionada nos relatos dos sujeitos de pesquisas. Desse modo, parte dos docentes acaba reservando um horário livre para ler os textos aos seus alunos com deficiência visual ou direcionando os familiares dos alunos a fazer isso em casa, por meio de anotações nas agendas. Diana e Eleno, pais de alunos, descreveram esses eventos e apresentaram suas impressões sobre o comportamento do professor:

Ela [Alana, professora de inglês] faz o que pode, ajuda a Fernanda na XXX [ela da escola] e aqui. Cansou de ler os livros que ela pede e fazer os exercícios com ele. Mas chega uma hora que não dá, ela tem as coisas dela pra resolver. E pede nossa ajuda. Eu leio muito devagar, meu filho... Minha visão não está lá essas coisas também. Mas tem primo e tio pra ler pra ela, quando a professora não pode (RESPONSÁVEL 1).

A XXX [professora de matemática da escola] sempre manda um recadinho na agenda, dizendo o que ela precisa ler de novo, quais exercícios vão ser cobrados. É bom, ajuda a gente a participar... Saber o que está acontecendo (RESPONSÁVEL 4).

No que diz respeito às ferramentas pedagógicas adotadas, professores da ONG Vida entrevistados relataram que os próprios materiais e brinquedos encontrados nas salas de recursos ou nos ambientes das escolas voltados para alunos com deficiência possuem problemas em seu formato. $\mathrm{Na}$ perspectiva desses, a significação tátil (o material didático deve possuir relevo perceptível e, tanto quanto possível, constituir-se de diferentes texturas para melhor destacar as partes componentes) e a fidelidade (o material deve possuir representação tão exata quanto possível do modelo original) são geralmente desconsideradas na confecção e utilização dos brinquedos, o que gera prejuízo às crianças, como evidenciam os relatos abaixo:

Posso lhe garantir que a sala de aula representa só metade na formação de aluno na escola. As brincadeiras no pátio e na sala, o ambiente familiar, o atendimento nos centros de apoio... Tudo isso faz parte da formação da criança, que 
precisa se sentir acolhida pra conseguir se desenvolver (...). E as brincadeiras nas escolas são fundamentais. Pena que há pouca ou quase nenhuma preocupação com os brinquedos. Os estímulos são diferentes, não tem como ser igual... Mas a gente só lembra-se dos livros e da impressora em Braille, esquece dos brinquedos (ASSISTENTE SOCIAL).

(...) pior é a mania de aumentar o tamanho dos brinquedos, isso atrapalha bastante. 0 [deficiente] visual precisa ter a noção do tamanho das coisas, e vai imaginar isso pegando nos objetos. Se você faz uma boneca com um rosto enorme ou com as pernas curtas, isso vai influenciar na maneira como ele percebe as bonecas (COORDENADOR PEDAGÓGICO).

Assim como foi constatado em outras investigações desenvolvidas sobre a deficiência visual no ensino fundamental e superior (Mantoan, 2002; Leite, 2013), os equívocos cometidos pelos professores também ocorrem dentro da sala de aula, no momento da exposição do conteúdo. Tais falhas serão discutidas a seguir.

\section{Principais falhas e acertosna prestação do serviço}

A análise das transcrições indica que alguns docentes também demonstraram que não acreditam na capacidade dos entrevistados de assimilar o conteúdo abordado em sala de aula. 0 estereótipo negativo de tais professores provocou uma série de eventos prejudiciais à formação da identidade de seus alunos deficientes visuais.

Ela achava que eu nunca ia aprender, que era difícil demais. E eu não pedia pra ela ditar as coisas, tinha vergonha. Até que meu irmão descobriu e disse ao meu pai. Melhorou um pouco, mas ela ainda acha que eu sou um peso na sala... Dá pra perceber (PAULO).

Faço nada lá, vou só pra brincar (...). A professora diz que está bom (GEÓRGIA).

Ela não me contou, fiquei sabendo, porque converso com a mãe dos outros alunos... A gente tem que procurar se informar, não é? Então descobri que Iarinha não estava fazendo os exercícios na sala. A professora dizia que não precisava. E quando ela não levava feito, também não era cobrada (ÁGATA).

Como está descrito acima, a crença de que o aluno cego ou com visão subnormal é incapaz de aprender associado ao excesso de piedade levaram os docentes a tratarem seus alunos de maneira diferenciada, os avaliando de maneira mais branda e comprometendo o seu desenvolvimento. Assim como as crianças videntes, o aluno do ensino fundamental que possui deficiência visual deve ser cobrado e avaliado pelos professores. Contudo, alguns alunos relataram que os professores simplesmente os liberavam das avaliações, assim como se observa abaixo:

Eu não precisei fazer a prova... Ela me passou. Disse que eu precisava vir mais vezes pra cá, estudar mais pra começar o ensino médio bem. Mas eu passei sem ter feito a prova (...). Foi muito bom, visse? (QUEIROZ).

[A professora] pediu que fizesse algumas tarefas e não me preocupasse, porque ia passar de ano (GEORGIA).

A má formação dos docentes, relatada acima, foi evidenciada em outros relatos. Foram encontrados indícios de que essa realidade é motivada por uma série de fatores, como a falta de incentivo dos gestores escolares da rede pública e privada, a baixa renumeração dos docentes - que os impedem de investir em sua capacitação e os obrigam a trabalhar em mais de uma instituição - e a própria falta de interesse de alguns docentes. A utilização da lousa sem que seja dito o que está sendo escrito, os diálogos em voz baixa ou com a utilização de mímicas são exemplos de situações comuns no dia-a-dia dos sujeitos de pesquisa entrevistados que interferem em seu aprendizado.

No sentido contrário dos relatos acima, o professor também é capaz de facilitar o processo inclusivo dos alunos. Uma das possíveis formas mencionadas é a aproximação entre as escolas regulares e as ONGs/associações de apoio aos deficientes. Esse relacionamento, quando estimulado pelos docentes, trouxe resultados positivos para os alunos. Os sujeitos de pesquisa mencionaram que os professores do ensino regular que procuram se aproximar dos professores da ONGs e associações em prol do acompanhamento dos seus alunos conseguem identificar as principais dificuldades de seus alunos e, consequentemente, encontram soluções efetivas com mais rapidez. Um 
exemplo foi relatado por Denise e se encontra abaixo:

\begin{abstract}
Ela veio conversar com "painho", pediu o telefone da minha professora aqui de matemática. Então, ela começou a mandar os exercícios pra professora daqui, sem passar por mim. A XXX [professora da ONG Lar] passava pro Braille e me mandava. Depois de eu resolver, ela escrevia as respostas e eu levava pra escola. Só assim que comecei a aprender mesmo (DENISE).
\end{abstract}

Além das ações realizadas na sala de aula, como a adaptação de gráficos, mapas e desenhos, pais de alunos relataram que alguns docentes buscaram ser o elo entre a escola e o lar das crianças, difundindo o aprendizado de seus alunos e explicando aos seus pais maneiras de contribuir para o desenvolvimento de seus filhos.

Meu tempo é curto, professor... E eu não me dou bem com as letras, fica difícil de ajudar. Mas ela faz questão de contar tudo que está acontecendo lá na sala, no que ele está com dificuldade... É um anjo (RESPONSÁVEL 2).

A partir dos relatos dos entrevistados, foi possível constatar que os alunos com deficiência visual carecem de auxílio dos professores no processo inclusivo desde os primeiros dias de aula até os demais meses. Esse processo inclusivo, porém, é prejudicado quando os educadores não conhecem as adaptações necessárias para o aprendizado do aluno e acabam adotando práticas exclusivas no ambiente educacional. Em contrapartida, os resultados também apontam que os professores podem estimular a adoção de pequenas alterações no ambiente escolar que facilitam o processo de inclusão. Outras considerações são feitas na seção seguinte.

\section{CONSIDERAÇÕES FINAIS}

As discussões relativas à inclusão no ambiente escolar são recorrentes no Brasil e abordam, dentre outros aspectos, políticas públicas, práticas e projetos que visam promover a melhoria do ensino para diversos grupos de cidadãos, como os deficientes visuais. Esta pesquisa apresenta uma discussão alinhada a essa temática, onde foi enfatizado o papel dos professores no processo inclusivo de crianças com deficiência visual. Especificamente, objetivou-se analisar o papel de docentes no processo inclusivo de alunos deficientes visuais do ensino fundamental. A partir dos resultados encontrados, alguns pontos merecem ser destacados.

Em primeiro lugar, foram encontrados indícios de que a integração entre os alunos bem conduzida pelos professores no início do período letivo, a realização de pequenas adaptações na estrutura física das salas e a aproximação dos professores com ONGs/associações de apoio aos deficientes são práticas inclusivas bem avaliadas pelos alunos. Contudo, outros professores demonstraram que não acreditam na capacidade dos entrevistados de assimilar o conteúdo abordado em sala de aula. Esse estereótipo negativo provocou uma série de eventos prejudiciais à formação da identidade de seus alunos deficientes visuais.

Em segundo lugar, foram encontrados indícios de que os beneficiados pelas ações inclusivas, em muitos casos, têm a noção exata de quais práticas são exclusivas e devem ser evitadas em sala de aula. Portanto, escutar os alunos é uma prática simples que deve ser estimulada. Para os professores, a altura da voz, os ruídos na sala de aula e a repetição das frases são exemplos de alguns aspectos que influenciam no aprendizado na sala de aula, como outros estudos (Costa, Neves, \& Barone, 2007; Barbosa-Lima \& Gonçalves, 2014) já haviam evidenciado.

Em relação à contribuição acadêmica desta pesquisa, é possível afirmar que esta investigação ampliou o debate sobre a inclusão de deficientes visuais, por considerar a escola um espaço social complexo que também deve ser investigado por pesquisadores de Marketing. Estudos alinhados à abordagem transformativa, em função de sua finalidade de promover o bem-estar do consumidor, devem considerar as práticas de consumo de serviços básicos, como a educação. Este estudo traz contribuições para o movimento de pesquisas transformativas por discutir o consumo em serviços de educação do ensino fundamental.

Investigações futuras podem ampliar 0 entendimento sobre a inclusão de pessoas com outras deficiências no ensino fundamental. Ao que parece, não há estudos nacionais sobre o comportamento de consumo de deficientes auditivos, uma interessante possibilidade de pesquisa. Apesar da recente contribuição de Faria (2015), compreender os hábitos de 
consumo de pessoas com deficiência intelectual também é outra lacuna de pesquisa.

\section{REFERÊNCIAS}

Alves, M. L. T., \& Duarte, E. (2004). A percepção dos alunos com deficiência sobre a sua inclusão nas aulas de Educação Física escolar: um estudo de caso. Revista Brasileira de Educação Física e Esporte, 28(2), 329-338.

Amaro, L., Meira, P., Camargo, S., Slongo, L., \& Machado, M. (2008). Em que posso ajudar? 0 varejo e os portadores de deficiência visual. Negócios e Talentos, 5.

ACR. Association For Consumer Research. (2017). Transformative Consumer Research. Recuperado em 11 janeiro, 2017, de http://www.acrwebsite.org/web/tcr/transfor mative-consumer-research.aspx.

Baker, S., Holland, J., \& Kaufman-Scarborough, C. (2007b). How consumers with disabilities perceive "welcome" in retail servicescapes: A critical incident study. Journal of Services Marketing, 21(3), 160-173.

Baker, S., Stephens, D., \& Hill, R. (2001). Marketplace experiences of consumers with visual impairments: Beyond the Americans with disabilities act. Journal of Public Policy \& Marketing, 20(2).

Barbosa, O. T. (2014). Estímulos táteis no ambiente de varejo: investigando a experiência de consumo de indivíduos com deficiência visual na perspectiva transformativa do consumidor. Dissertação de Mestrado, Universidade Federal de Pernambuco, Recife, PE, Brasil.

Barbosa-Lima, M. C., \& Gonçalves, C. O. (2014). 0 ensino não formal e a formação de um professor de física para deficientes visuais. Ensaio Pesquisa em Educação em Ciências, 16(2).

Castaman, A. S. (2006). Percursos e discursos de normalização na educação especial. Revista Divisa, 4, 23-30.

Censo Escolar de 2015. (2015). INEP, Brasília. Recuperado 11 junho, 2016, de http://portal.inep.gov.br/censo-escolar.

Childers, T., Kaufman-Scarborough, C. (2009). Expanding opportunities for online shoppers with disabilities. Journal of Business Research, 62(5), 572-578.

Coelho, P. F. C. (2015). A Pesquisa Transformativa do Consumidor: reflexões e diretrizes para pesquisadores brasileiros. E\&G Economia $e$ Gestão, 15(40).

Coelho, P., Orsini, A., \& Abreu, N. (2016). Os encontros de serviço de deficientes visuais em
Instituições de Ensino Superior. Revista Pensamento Contemporâneo em Administração, 10(2), p. 65-79, 2016.

Costa, L.G., Neves, M. C., \& Barone, D. (2007). O ensino de Física para deficientes visuais a partir de uma perspectiva fenomenológica. Ciência e Educação, 2(2), p. 143-153, 2007.

Creswell, J. (2007). Projeto de pesquisa: métodos qualitativo, quantitativo e misto. Porto Alegre: Artmed.

Dall'acqua, M. (2002). Intervenção no ambiente escolar: estimulação visual de uma criança com visão subnormal ou baixa visão. São Paulo: Editora UNESP.

Damascena, E., \& Farias, S. (2013). Os elementos sensoriais em supermercados: um estudo junto a pessoas com deficiência visual na perspectiva da pesquisa transformativa do consumidor. Anais do Encontro Nacional da Associação Nacional de Pós-Graduação e Pesquisa em Administração, Rio de Janeiro, RJ, Brasil, 37.

Davis, B., \& Pechmann, C. (2011). Introduction to the special issue on transformative consumer research for the journal of research for consumers. Journal of Research for Consumers, 19.

Diretrizes Nacionais para a Educação Especial na Educação Básica. (2001). Brasília: MEC/SEESP.

Faria, M. (2015). A eterna criança e as barreiras do ter: consumo de pessoas com Síndrome de Down e suas famílias. Tese de Doutorado, Universidade Federal do Rio de Janeiro, Rio de Janeiro, RJ, Brasil.

Faria, M., \& Motta, P. (2012). Pessoas com deficiência visual: Barreiras para o turismo de lazer. Revista Turismo em Análise, 23, 691-717.

Faria, M., Silva, J., \& Ferreira, J. (2012). The visually impaired and consumption in restaurants. International Journal of Contemporary Hospitality Management, 24(3).

Fernandes, S. H.. (2011). Relações entre o "visto" e o "sabido": As representações de formas tridimensionais feitas por alunos cegos. Revista Iberoamericana de Educação Matemática, 26,137-151.

Ferreira, J. R. (2006). Educação especial, inclusão e política educacional: notas brasileiras. In: RODRIGUES, D. (Org.). Inclusão e educação: doze olhares sobre a educação inclusiva. 1. ed. São Paulo: Summus, 1, 85-113.

Figueiredo, R. M., \& Kato, O. M. (2015). Estudos nacionais sobre o ensino para cegos: uma revisão bibliográfica. Revista Brasileira de Educação Especial, 21(4), 477-488. 
Fiorini, M. L., Deliberato, D., \& Manzini, E. J. (2013). Estratégias de ensino para alunos deficientes visuais: A proposta curricular do estado de São Paulo. Motriz: Revista de Educação Física, 19(1), 62-73.

Franco, J. R. et al. (2007). Orientação educacional às famílias com deficiência visual. In: MANZINI, E. J. (Org.). Inclusão de alunos com deficiência na escola: os desafios continuam. Marília: ABPEE/FAPESP.

Gaskell, G. (2002). Entrevistas individuais e grupais. In: BAUER, M.; GASKELL, G. Pesquisa qualitativa com texto, imagem e som. Rio de Janeiro: Vozes, 64-89.

Gorni, D. (2007). Ensino fundamental de nove anos: estamos preparados para implantá-lo? Ensaio: Avaliação das Políticas Públicas Educacionais, 15(54), 67-80.

Jovchelovich, S., \& Bauer, M. (2002). Entrevista Narrativa. In: Bauer MW, Gaskell G. Pesquisa qualitativa com texto, imagem e som: um manual prático. Petrópolis: Vozes.

Kaufman-Scarborough, C., \& Childers, T. (2009). Understanding markets as online public places: insights from consumers with visual impairments. Journal of Public Policy \& Marketing, 28(1), 16-28.

Laplane, A. L.; Caiado, K. R. (2012). Uma década de educação especial. In: Debora Cristina Jeffrey; Luis Enrique Aguilar. (Org.). Política educacional brasileira. 1 ed. Campinas: Mercado de Letras, 1, 119-142.

Lei de Diretrizes e Bases da Educação Nacional, 20 dezembro de 1996. Recuperado 11 julho, 2016,

http://www.planalto.gov.br/ccivil_03/leis/L9 394.htm

Lei no 13.146, de 6 de julho de 2015. Institui a Lei Brasileira de Inclusão da Pessoa com Deficiência. Recuperado em 10 setembro, 2015,

dehttp://www.planalto.gov.br/ccivil_03/

_Ato2015-2018/2015/Lei /L13146.htm

Lei no 13.146, de 6 de julho de 2015. Institui a Lei Brasileira de Inclusão da Pessoa com Deficiência. Recuperado em 10 setembro, 2015,

dehttp://www.planalto.gov.br/ccivil_03/ _Ato2015-2018/2015/Lei /L13146.htm

Leite, M. (2013). Educação inclusiva na percepção de professores dos anos iniciais do ensino fundamental: um estudo de caso em escola pública estadual de Minas Gerais. Anais do Encontro Nacional da Associação Nacional de Pós-Graduação e Pesquisa em Administração, Rio de Janeiro, RJ, Brasil, 37.
Lippe, E., Alves, F., \& Camargo, E. (2012). Análise do processo inclusivo em uma escola estadual no município de Bauru: a voz de um aluno com deficiência visual. Revista Ensaio, 14(2), 81-94.

Mantoan, M. (2002). Ensinando a turma toda. Pátio: Revista Pedagógica, 20, 18-23.

Mick, D., Pettigrew, S., Pechmann, C., \& Ozanne, J. (2012). Origins, qualities, and envisionments of Transformative Consumer Research. In: Mick, D.., Pettigrew, S.

Pechmann, C., \& Ozanne, J. (2012). Transformative consumer research for personal and collective well being: reviews and frontiers. NY: Routledge.

Oliveira, A. A. (2006). Flexibilizações e adequações Curriculares para Atendimento às Necessidades Educacionais Especiais. SINOPMT: CEACD/UNEMAT; Editora UNEMAT.

Oliveira, R. P. (2007). Da universalização do ensino fundamental ao desafio da qualidade: Uma análise histórica. Educação \& Sociedade, Campinas, 28(100), 661- 690.

Petkus, E. (2010). Incorporating transformative consumer research into the consumer behavior course experience. Journal of Marketing Education, 32(3) 292-299.

Pinheiro, M., Pena da Silva, E., \& Rodrigues, L. (2008). 0 ir e vir dos deficientes visuais: barreiras arquitetônicas e acadêmicas na UFMT. Inclusão Social, 3(1), 48-65.

Pinto, M. \& Freitas, R. (2013). O que os olhos não veem o coração não sente? Investigando experiências de compra por deficientes visuais no varejo de roupas. REGE - Revista de Gestão, 20(3), 387-405.

Pinto, M. et al. (2016). TCR: reflexões, diretrizes e uma análise do campo no Brasil. RIMAR Revista Interdisciplinar de Marketing, 6(2), 5466.

Política nacional de educação especial na perspectiva da educação inclusiva. (2008). Brasília: MEC/SEESP.

Razuck, R. C., \& Guimarães, L.B. (2014). 0 desafio de ensinar modelos atômicos a alunos cegos e o processo de formação de professores. Revista de Educação Especial, 27(48), 141-154.

Regiani, A. M. \& Mol, G. S. (2013). Inclusão de uma aluna cega em um curso de licenciatura em Química. Ciências \& Educação (Bauru), 19(1), 123-134.

Rosa, F. M. \& Baraldi, I. M. (2015). O uso de narrativas (auto)biográficas como uma possibilidade de pesquisa da prática de professores acerca da Educação (Matemática) Inclusiva. Bolema, 29(53), 936-954.

Santos, L. \& Vieira, L. (2006). Agora seu filho entra mais cedo na escola: A criança de seis anos no 
Inclusão da criança com deficiência visual em serviços de ensino sob a perspectiva da pesquisa transformativa do consumidor

ensino fundamental em Minas Gerais. Educação \& Sociedade, 27(96), 775-796.

Secretaria de Educação Fundamental. (1998). Parâmetros curriculares nacionais: adaptações curriculares. Brasília: MEC/SEF/SEESP.

Sigolo, S. R., \& Oliveira, A. M. (2008). Relação famíliaescola e o processo de inclusão escolarsubsídios para orientação família. In: MENDES, E.G.; ALMEIDA, M. A.; HAYASHI, M. C. P. I. (Org.). Temas em Educação Especial: conhecimentos para fundamentar a prática.
Araraquara, SP: Junqueira \& Marin; Brasília, DF: CAPES-PROESP.

Viralonga, C. A., \& Caiado, K. R. M. (2013). Processos de escolarização de pessoas com deficiência visual. Revista Brasileira de Educação Especial, 19(1), 61-78.

Vygotski, L. S. (1997). Obras escogidas V: Fundamentos de defectologia. Madrid: Gráfica Rogar.

Zucherato, B., \& Freitas, M. I. (2011). A construção de gráficos táteis para alunos deficientes visuais. Ciência em Extensão, 7(1), 24-41.

\title{
Inclusion of the Visually Impaired Child in Educational Services from the Perspective of Transformative Consumer Research
}

\begin{abstract}
This research has the objective to analyze the role of teachers in the inclusive process of visual impairment students of elementary schools. Therefore, an exploratory qualitative which data were collected through narrative interviews with 16 visually impaired students and in-depth interviews with five relatives and six teachers and managers from an NGO dealing with the visually impaired. The results indicate that teachers are able to promote student inclusion or are responsible for excluding practices. The results show that teachers are actors who can promote the students inclusion students, through various initiatives, such as encouraging the integration of students with other colleagues and adapting teaching tools. However, teachers may encourage exclusive practices, such as ignoring the presence of these students in the classroom or expressing their disbelief at the learning potential of visually impaired children.
\end{abstract}

Keywords: transformative consumer research, school inclusion, visual impairment. 